\title{
CELASTROL NANOEMULGEL FORMULATION AND IN VITRO PENETRATION TEST
}

\author{
NUR ALAM ABDULLAH ${ }^{1}$, MAHDI JUFRI ${ }^{1}$, ABDUL MUNIM1ㅜ, FADLINA CHANY SAPUTRI ${ }^{1}$ \\ ${ }^{1}$ Laboratory of Nanotech Pharmacy, Faculty of Pharmacy, Universitas Indonesia, Depok, 16424, Indonesia \\ Email: mahdi.jufri@farmasi.ui.ac.id
}

Received: 17 Feb 2020, Revised and Accepted: 20 Jun 2020

\begin{abstract}
Objective: To obtain formulations of Celastrol (Cst) nanoemulgel via transdermal route. Celastrol is classified in BCS 4 class as an anti-inflammatory drug. These routes are considered to reduce the risk of Celastrol side effects and have the same characteristics as skin morphology.

Methods: Celastrol nanoemulgel was prepared by a high-pressure homogenizer (HPH) technique. To find the optimum nanoemulsion area by using the Chemix 7.00 ternary phase program. Celastrol nanoemulgel was evaluated by measuring the particle size, PDI, morphology, zeta potential, stability tests and in vitro using Franz diffusion cell

Results: Results showed the ideal formula based on the ternary phase diagram using chemix 7.00 is oil: smix: water (5:45:50), with particle size $89.9 \pm 5 \mathrm{~nm}$, PDI 0.1 , and zeta- $21 \mathrm{mV}$. The morphological shape is quite spherical $\leq 100 \pm 5 \mathrm{~nm}$. The pH value of this formula is 4.5 , which compatible with the $\mathrm{pH}$ of the skin. The highest recovery rate of Celastrol and encapsulation efficiency (EE) were formulas $3 \mu \mathrm{g} / \mathrm{ml}$ and $5 \mu \mathrm{g} / \mathrm{ml}$, with EE $91.70 \%$ and $94.54 \%$, respectively. In vitro test results showed that the formula $3 \mu \mathrm{g} / \mathrm{ml}$ and $5 \mu \mathrm{g} / \mathrm{ml}$ give better penetration results than the formula $2.5 \mu \mathrm{g} / \mathrm{ml}$. Thus, Celastrol nanoemulgel formula has good potential to be developed as a transdermal anti-inflammatory drug.
\end{abstract}

Conclusion: Transdermal nanoemulgel containing Celastrol has been successfully developed with particle size $\leq 200 \pm 2 \mathrm{~nm}$.

Keywords: Celastrol (Cst), Transdermal nanoemulgel, Anti-inflammatory, Franz diffusion cells (SDF)

(C) 2020 The Authors. Published by Innovare Academic Sciences Pvt Ltd. This is an open access article under the CC BY license (http://creativecommons.org/licenses/by/4.0/) DOI: http://dx.doi.org/10.22159/ijpps.2020v12i8.37167. Journal homepage: https://innovareacademics.in/journals/index.php/ijpps.

\section{INTRODUCTION}

Celastrol (Cst) is a nutritious compound derived from Tripterygium wilfordii Hook $F$ (TWFH) isolates. It can be used to treat several immune system disorders and neuroprotective, as an antiinflammatory for various causes of inflammation, especially autoimmune disorders [1].

Celastrol is part of the pentacyclic Triterpenoid natural compound from the methyl quinone family. This class of compounds has antiinflammatory and anti-pain activity. Many studies about Celastrol's pharmacological activity as an anti-inflammatory, found that the compound works at the target receptors that trigger inflammation from various pathways. These include cytokine pathways (TNF- $\alpha$, IL1 , IL- 6 and IL-8), as well as the formation of cyclooxygenase 1 and 2 pathways (COX 1 and 2). through inhibiting catalytic activity (sPLA2IIA), which produces the eicosanoid formation of arachidonic acid (AA)) [2]. Celastrol's physical and chemical properties make it difficult to dissolve in water, which causes problems with the developing of Celastrol as a formula. Celastrol has a Log P value of 5.63, which, in the pharmaceutical system, is categorized as Biopharmaceutical Classification System 4 (BCS 4). Pharmaceutical drugs, in the BCS 4 category, have very low solubility and permeability.

Therefore, delivering this active substance requires a formula development approach, and this study will use the nanoparticle system. Theoretically, the smaller the nanoparticle size, the more it can increase compound's ability of these compounds to be absorbed or the greater the surface area to penetrate a membrane. Changing the drug administration route from oral to transdermal means the Celastrol compounds can be formulated in line with the development of nanotechnology formulas [3]. Formulations can be developed from to Celastrol with the nanotechnology approach, which aims to improve these compounds' solubility and bioavailability. Among them are the phytosome Celastrol, Celastrol liposomes Celastrol nanomicel, NLC Celastrol, and the most recent, Niosom Celastrol and Dendrimers Celastrol. The method was developed into peroral, IP, and topical routes. The study results concluded that Celastrol developed into nanotechnology increased the absorption efficiency (EE) to $98.06 \%$ with an average particle size of $89.6 \pm 7.3 \mathrm{~nm} \leq 100$ $\mathrm{nm}$ and zeta potential of $87.8 \pm 5.8 \mathrm{mV}$ [4-8].

There are no published studies on the Celastrol compound's potential if it is developed to be administrated via other routes. For example, transdermal routes have similar characteristics to nanoemulsion technology. It is known that nanoemulsion, when developed into the transdermal route, shows optimal work results with promising pharmaceutical dosage forms $[9,10]$.

The transdermal nanoemulgel has properties in common with the stratum corneum (sc), which is the main obstacle of the transdermal route. The oil base content on the nanoemulgel base will provide its own benefits in therapy.

The Nanoemulgel's ingredients can adhere to the skin's surface and gradually increase its hydration. They can also can stretch the skin's permeability, which causes changes in polarity, fluidity, and fat exchange between cells in the skin, ultimately facilitating active substances penetration into systemic tissue.

When developing a transdermal route, the active ingredient must have considered, along with characteristics such as inertness, constant in various temperatures, stable in acidic conditions $(\mathrm{pH})$, polarity, toxicity, allergenic, molecular weight $<$ around $450 \mathrm{Da}$, and low melting point, Further, it should not irritate the skin. Celastrol meets the above conditions so it is worth trying in its development into the transdermal route with the nanoemulgel dosage form $[11,12]$.

This study aims to develop a transdermal nanoemulgel Celastrol preparation formula by evaluating its anti-inflammatory activity in vitro and in vivo.

\section{MATERIALS AND METHODS}

Chemicals and animals

The materials used in this study are; Celastrol standard obtained from Xi'an Fengzu Biological Technology Co., Ltd., and Celastrol samples obtained from Xi'an Huisun Bio-Tech Co., L. td (PRC). 
Isopropilmiristat (IPM), Polysorbatum 80 (Tween 80), Propylenglycolum (PG), API (Aqua Pro Injection), Ethanol 96\%, Methyl Paraben, Propyl Paraben, and 305 sepigels, from PT. Bratako Tbk., (Jakarta). Merck methanol pro analyse, Acetonitrile pro analyse merck, formic acid pro analysis, The tools used are; duran and pyrex chemical glass tools, including beaker glass $50 \mathrm{ml}, 100 \mathrm{ml}, 250 \mathrm{ml}$, $500 \mathrm{ml}, 1500 \mathrm{ml}, 2000 \mathrm{ml} .10 \mathrm{ml}, 50 \mathrm{ml}, 100 \mathrm{ml}$ measuring cups. 7.5 $\mathrm{cm}$ amplifier cup, stirring rod, measuring flask $2 \mathrm{ml}, 5 \mathrm{ml}, 10 \mathrm{ml}, 50$ $\mathrm{ml}, 100 \mathrm{ml}$ and $250 \mathrm{ml}$, thermometer, pH meter, Cole Parmer® Viscometer, Shimadzu HPLC, Particles size analyzer (PSA) Malvern $®$, Ultra Turrax 20,000 rpm T25 Digital Homogenizer (120 V USA), GEA Brazilian high-pressure homogenizser (HPH)

\section{Determination of standard Celastrol calibration curves}

First, we placed $10 \mathrm{mg}$ of the standard Celastrol in a $10.0 \mathrm{ml}$ volumetric flask and added methanol as a solvent to the mark. Then dilution was made as many as 6 (six) concentrations, namely 5 ppm, 10 ppm, 50 ppm, 100 ppm, 250 pp, and 500 ppm. Subsequently, an analysis was carried out by HPLC at a wavelength of $230 \mathrm{~nm}$ using an inverted phase c-18 column with a mobile phase of acetonitrile: $0.1 \%$ solution of formic acid $(85: 15) \mathrm{v} / \mathrm{v}$. The results were calculated to obtain a linear calibration curve [13]

Optimization of nanoemulsion areas with ternary phase diagrams

The optimizing process used the pseudo ternary triangle method which aims to obtain a stable nanoemulsion area. This process involved mixing surfactant and co-surfactant materials from various concentrations that were suitable for the active substance's physicalchemical properties. The nanoemulsion optimization was carried out by a high energy method involving stirring using an ultraturrax $20,000 \mathrm{rpm}$ for $15 \mathrm{~min}$. The nanoemulsion area was arranged using Chemix 7.00 software. Previous research used the Chemix 7.00 program to find good, stable nanoemulsion areas in the pseudo ternary triangle to facilitate further work [14]

Nanoemulsion was developed using Isopropylmiristate (IPM) as oil phase, tween 80 as the surfactant, and propylene glycol as cosurfactant, while distilling water as the water phase. The formulas were compared based on the area of nanoemulsion formed as a result of the Chemix 7.00 program. For example, a mixture of surfactants and co-surfactants called smixes (9:1 to 1: 9) will show stable results. All nanoemulsion formula results were carried out by the desired particle size analysis in the research objective of $100 \mathrm{~nm}$ for the transdermal route using a particle size analyzer (PSA) Malvern $®[15]$.

Using pseudoterner models in the manufacture of nanoemulsion formulations was considered the best way to determine the composition of the three constituent elements in nanoemulsion preparations

If the particle size were still bigger than $500 \mathrm{~nm}$, we used a HPH machine with a setting of 600 bars and 8 cycles [16]

\section{Selection of selected formulas from the nanoemulsion area}

After obtaining the nanoemulsion area from the Chemix 7.00 program, we selected the best, most stable formula and entered the active Celastrol substance into the nanoemulsion.

Celastrol inserted into the nanoemulsion formula, was divided into 3 (three) forms of Celastrol doses of $2.5 \mu \mathrm{g} / \mathrm{ml}, 3 \mu \mathrm{g} / \mathrm{ml}$ and $5 \mu \mathrm{g} / \mathrm{ml}$ respectively.

\section{Manufacture of Celastrol nanoemulgel}

We obtained 2 grams of sepigel ${ }^{\circledR} 305$ gel added $20 \mathrm{ml}$ of CO2-free distilled water and then put it into $100 \mathrm{ml}$ of nanoemulsion preparations for each Celastrol dose while stirring using ultra turrax® 20,000 rpm for 15 min until homogeneous [17]

The F1 control, F2 control and F3 control were made with a base of gel sepigel@ 305. Each Celastrol dose $(2.5 \mu \mathrm{g} / \mathrm{ml}, 3 \mu \mathrm{g} / \mathrm{ml}$ and 5 $\mu \mathrm{g} / \mathrm{ml}$ ) was added to a container containing 100 added gel bases $0.1 \%$ DMSO is stirred using ultra turrax ${ }^{\circledR}$ for 15 min with 20,000 RPM [18].

\section{Evaluation of Celastrol nanoemulgel preparations}

Organoleptic, pH, and homogeneity testing

Organoleptic testing of Celastrol nanoemulgel preparations carried out by direct observation of the preparations physical apperances, starting from the physical form of nanoemulgel, and the characteristic odor of Celastrol compounds [19].

\section{pH measurement}

One gram of Celastrol nanoemulgel preparations was obtained from each formula, put into a $100 \mathrm{ml}$ glass beaker, dissolved with $100 \mathrm{ml}$ distilled water, and stirred using a stirring rod. We measured the $\mathrm{pH}$ value using a $\mathrm{pH}$ measuring device brand Eutech Instrument $\mathrm{pH}$ meter 510 (Singapore). Ideally, the $\mathrm{pH}$ that penetrates the skin via the transdermal route is 4.5-6.5. Each Celastrol nanoemulgel preparation that had been formed was tested for homogeneity by weighing 1 gram of the preparation and then sprinkling it on a transparent glass plate. Visual observation was carried out under bright light [20].

\section{Particle size, polarity index (PDI), zeta potential}

The test is carried out using each Celastrol nanoemulgel that has been formed in a $1 \mathrm{mg}$ weigh carefully and then dissolved with distilled water up to $9 \mathrm{ml}$. The solution was taken as much as $100 \mu \mathrm{l}$ and put into a PSA cuvette container and then analyzed using a Marvern ${ }^{\circledR}$ particle size analyzer at $25^{\circ} \mathrm{C}[21]$.

\section{Cycling test}

Dispersion stability testing is carried out in 6 (six) cycles. Each cycle starts from $4 \pm 2{ }^{\circ} \mathrm{C}$ for $24 \mathrm{~h}$; the preparation is then transferred to

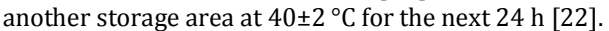

\section{Viscosity}

Viscosity was measured using a Cole Parmer® viscometer [23, 24].

\section{Morphology of the preparation}

The morphological examination of the preparations was carried out using a JOEL (JEM-1010) JOEL Brand Transmission Electron Microscopy. The procedure was carried out by taking $0.2 \mu \mathrm{l}$ of a Celastrol nanoemulgel preparation using uranyl acetate dye $2 \%$ $(\mathrm{w} / \mathrm{v}) \quad 0.2 \mu \mathrm{l}$, which was dripped on the cooper grid plate. Furthermore, observations were made at a magnifications of 30,000 50,000 and 100,000 times $[25,26]$.

\section{Test the physical stability of the preparation}

The Celastrol nanoemulgel preparations were tested under three different temperatures for $12 \mathrm{w}$, including odor, color, and $\mathrm{pH}$. Each preparation was stored at a cold temperature at $4 \pm 2{ }^{\circ} \mathrm{C}$, then at room temperature at $28 \pm 20 \mathrm{C}$, and lastly at a hot temperature at $40 \pm 2{ }^{\circ} \mathrm{C}$ [27].

\section{Franz penetration test cell diffusion (SDF)}

The penetration test phase of Celastrol nanoemulgel preparation was carried out in vitro at a $\mathrm{pH}$ of 7.4 using a phosphate buffer solution. The procedure added $0.2 \mathrm{M}$ potassium dihydrogen phosphate to $39.1 \mathrm{ml}$ of $0.2 \mathrm{~N}$ sodium hydroxide supplemented with C02-free distilled water to a pH of 7.4 [28]

The the skin test was conducted on male rats, aged $8 \mathrm{w}$, with a bodyweight of $\pm 200-250 \mathrm{~g}$, The rats were anesthetized using $0.1 \%$ ketamine by inhalation. The rat's skin was cleaned with a hair shaver, and the skin was sliced by removing the fat part slowly. The obtained skin was soaked into a phosphate buffer solution of $\mathrm{pH} 7.4$ for $30 \mathrm{~min}$ at $4 \mathrm{C}$, which can only be used within the first $24 \mathrm{~h} \mathrm{[29].}$

From the Franz diffusion cells tool calibration results, a surface area of $1,766 \mathrm{~cm} 2$ and an average compartment volume of $16.0 \mathrm{ml}$ were obtained. The rat skin position was placed in the donor compartment. Then a 1.0-gram sample preparation is carefully placed over the skin, which contained a phosphate buffer solution at a pH of 7.4 at the receptor site. A sampling of $1.0 \mathrm{ml}$ was carried out at 8 points with a certain time interval of $2,4,6,8,10,12,20,24 \mathrm{~h}$ at $370 \mathrm{C}$ from the receptor compartment. The most important thing in using SDF is to keep the sink well maintained by entering the same amount in the receptor compartment, that is $1.0 \mathrm{ml} \mathrm{[30].}$ 
First, $1.0 \mathrm{ml}$ of the sample was taken from the receptor compartment channel and put into a $5.0 \mathrm{ml}$ flask, which was sufficient with the methanol pro analyzed solvent (p. a) to the mark limit on the flask Then $20.0 \mu \mathrm{l}$ was taken and analyzed by HPLC at a wavelength of $230 \mathrm{~nm}$ using a mobile phase of acetonitrile: $0.1 \%$ formic acid solution (85:15) flow rate of $1.0 \mathrm{ml}$. The area from the HPLC analysis results is entered into the calibration curve equation, and the Celastrol content is calculated in the receptor compartment. All HPLC analyses were performed 3 (three) times [31].

\section{Assay of the Celastrol}

For each dose of $2.5 \mu \mathrm{g} / \mathrm{ml}, 3 \mu \mathrm{g} / \mathrm{ml}$, and $5 \mu \mathrm{g} / \mathrm{ml}, 1$ gram of Celastro nanoemulgel preparation as added to a solvent of $5 \mathrm{ml}$ methano pro-analysis (pa) in a centrifuge tube, then centrifuged thoroughly at $4500 \mathrm{rpm}$ for $30 \mathrm{~min}$. The supernatant formed in a $100.0 \mu \mathrm{l}$ pipette and analyzed by HPLC at a wavelength of $230 \mathrm{~nm}$ using a mobile phase of acetonitrile: $0.1 \%$ formic acid solution (85:15) flow rate o $1.0 \mathrm{ml}$. The area of HPLC analysis results obtained was calculated Celastrol levels based on the calibration curve equation [32]

\section{Determination of Celastrol levels in nanoemulgel preparations}

For each dose of the Celastrol nanoemulgel preparation, $500 \mathrm{mg}$ was added to a centrifuge tube with a methanol pro-analysis (p. a) solvent to $5 \mathrm{ml}$. The solution was centrifuged $4500 \mathrm{rpm}$ for $30 \mathrm{~min}$. The precipitate obtained was separated from the supernatant, and then the precipitate was dissolved with methanol up to $5 \mathrm{ml}$ filtered using a $0.22 \mu \mathrm{m}$ syringe filter. The obtained filtrate was analyzed by HPLC at a wavelength of $230 \mathrm{~nm}$ using a mobile phase of acetonitrile: $0.1 \%$ formic acid solution (85:15) flow rate of $1.0 \mathrm{ml}$ The results of HPLC analysis obtained in calculating Celastrol levels are based on the calibration curve equation [33]

\section{Determination of cumulative levels}

All hourly measurements of Celastrol levels obtained in the in vitro Franz diffusion cells (SDF) test, were graphed between the cumulative amounts of Celastrol penetrated per unit time of sampling. So that the cumulative levels of Celastrol, which will penetrate the surface area of the skin membrane of rats, the following equation was used [34].

$$
Q=C_{n} V+\sum_{t=1}^{n-1} C_{i} S / A
$$

Information:

$\mathrm{Q}=$ cumulative number of Celastrol per unit surface area membrane $(\mu \mathrm{g} / \mathrm{cm} 2)$

$\mathrm{Cn}=$ Celastrol concentration $(\mu \mathrm{g} / \mathrm{cm} 2)$ for each extract Sample

$\mathrm{V}=$ Franz diffusion cell volume $(\mu \mathrm{l})$

Vs = sample volume $(\mu \mathrm{l}) \mathrm{n}-1$

$\sum=$ total Celastrol concentration $(\mu \mathrm{g} / \mathrm{ml})$

$\mathrm{t}=1$ for each sample from 1 to $\mathrm{n}-1$

$\mathrm{S}$ = sample volume, $1.0 \mathrm{ml}$

$A=$ Surface area of the membrane, which is $1.7666 \mathrm{~cm} 2$

Flux is obtained from a graph with steady state conditions based on Fick's Law

$$
i=\frac{M}{s, t}
$$

Information:

$\mathrm{J}=$ Flux under steady state $\left(\left(\mu \mathrm{g} \mathrm{cm} 2 \mathrm{~h}^{-1}\right)\right.$

$\mathrm{S}=$ Area of diffusion area $(\mathrm{cm}-2)$

$\mathrm{M}=$ Amount

\section{Determination of Celastrol nanoemulgel type}

Each nanoemulgel type, initially weighed $\pm 250 \mathrm{mg}$ nanoemulgel Celastrol preparation, was placed on the object-glass, then dripped Sudan III for the oil phase and methylene blue for the water phase. The object-glass was again placed on the first plate that contained the preparation, and pressed precisely, for improved accuracy. Then the samples on these plates were observed on an Olympus $\AA$ electron microscope (maximum enlargement). Microscope examination results showed that the nanoemulgel preparations developed were nanoemulsion type M/A or O/W.

\section{RESULTS AND DISCUSSION}

The Celastrol calibration curve is linear with a correlation coefficient $(\mathrm{r} 2=0.9992)$ in the concentration range from 5 to $500 \mu \mathrm{g} / \mathrm{ml}$ as shown in fig. 1.

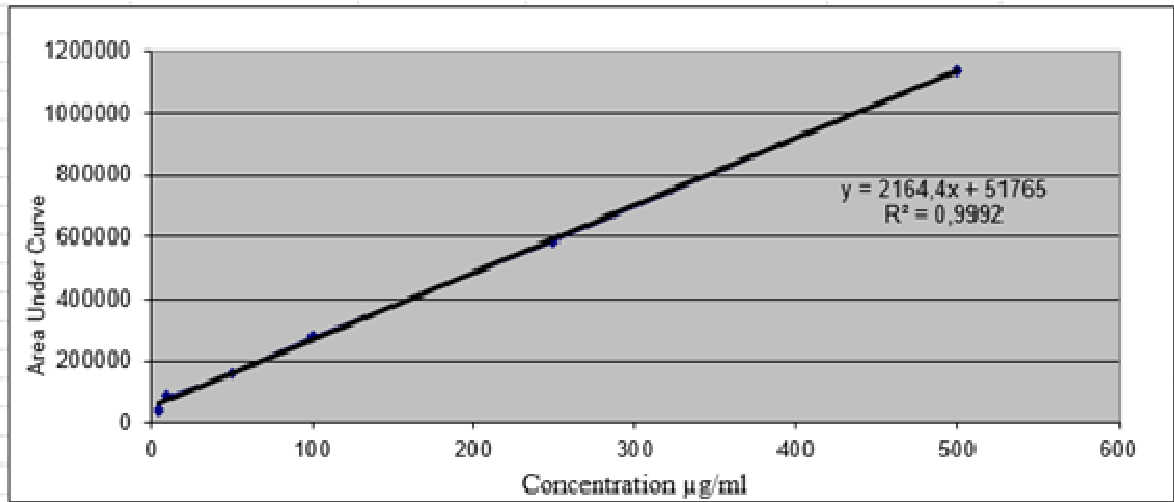

Fig. 1: Calibration curve of celastrol

The results of the evaluation of preparations of Celastrol nanoemulgel preparations were obtained each dose. the physical form of nanoemulgel is opaque white color following the FG-NCP transparent color indicator

The $\mathrm{pH}$ measurements obtained with different $\mathrm{pH}$ values tended to fall by 2 points from the first day of testing before the 12-day cycle stability test every $24 \mathrm{~h}$. The first time the Celastrol nanoemulgel has just been prepared for direct $\mathrm{pH}$ testing using a $\mathrm{pH}$ measuring device brand Eutech Instrument $\mathrm{pH}$ meter 510 (Singapore). The first $\mathrm{pH}$ was $7.1924 \mathrm{~h}$, the $\mathrm{pH}$ value dropped by 2 points to 4.79 and during the next $24 \mathrm{~h}$ of the cycle, the pH values were $4.77,4.79,4.90,4.95$ and 4.93 . The $\mathrm{pH}$ value of Celastrol can cause a decrease to around $4.6[35]$ 
Organoleptic homogeneity testing shows that all dosage of Celastrol nanoemulgel are evenly shaped, with no visible layers or forms of damage from nanoemulgel preparations, such as coalescence, sedimentation, flocculation, cremation, or breaking.

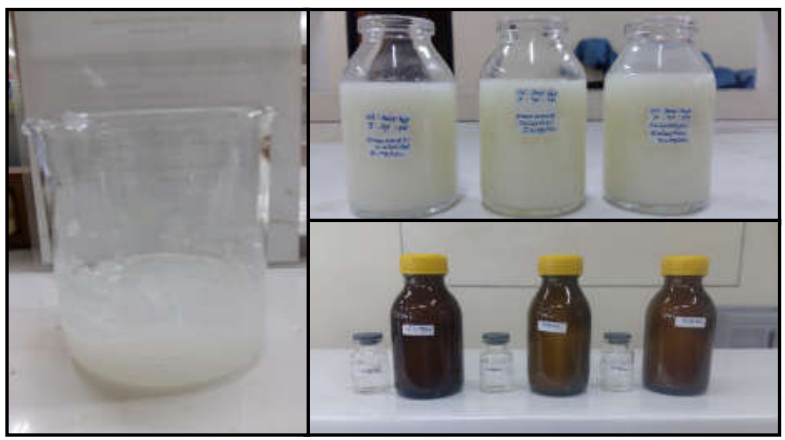

Fig. 2: Example availability. a. Celastrol Nanoemulsion. b. Nanoemulgel Celastrol c. Base gel form of sepigel 305®

Optimization results of the ternary ratio $1: 9$ to $9: 1$ phase of oil, smix (tween $80+\mathrm{PG}$ ) and water from a ratio of $90 \%$ water to $50 \%$ water obtained by nanoemulsion bases according to a ternary ratio of 5:45:50 and oil phase IPM: smix (tween80+PG): water.

Table 1: Celastrol nanoemulgel formula

\begin{tabular}{|c|c|c|c|c|c|c|}
\hline \multirow{2}{*}{$\begin{array}{l}\text { Composition } \\
\mu \mathrm{g} / \mathrm{ml} / \%\end{array}$} & \multicolumn{6}{|l|}{ Formula } \\
\hline & $\begin{array}{l}\text { F1 } \\
(\mu \mathrm{g} / \mathrm{ml})\end{array}$ & $\begin{array}{l}\text { F2 } \\
(\mu \mathrm{g} / \mathrm{ml})\end{array}$ & $\begin{array}{l}\text { F3 } \\
(\mu \mathrm{g} / \mathrm{ml})\end{array}$ & $\begin{array}{l}\text { F4+DMSO 0.1\% } \\
(\mu \mathrm{g} / \mathrm{ml})\end{array}$ & $\begin{array}{l}\text { F5+DMSO } 0.1 \% \\
(\mu \mathrm{g} / \mathrm{ml})\end{array}$ & $\begin{array}{l}\text { F6+DMSO 0.1\% } \\
(\mu \mathrm{g} / \mathrm{ml})\end{array}$ \\
\hline Celastrol & 2.5 & 3 & 5 & 2.5 & 3 & 5 \\
\hline IPM & 5 & 5 & 5 & 5 & 5 & 5 \\
\hline Smix & 45 & 45 & 45 & 45 & 45 & 45 \\
\hline Aquadest & 50 & 50 & 50 & 50 & 50 & 50 \\
\hline Metil Paraben & 0.05 & 0.05 & 0.05 & 0.05 & 0.05 & 0.05 \\
\hline Propil paraben & 0.05 & 0.05 & 0.05 & 0.05 & 0.05 & 0.05 \\
\hline Sepigel $^{\circledR} 305$ & 2 & 2 & 2 & 2 & 2 & 2 \\
\hline $\mathrm{CO}_{2}$ Free water & 20 & 20 & 20 & 20 & 20 & 20 \\
\hline
\end{tabular}

IPM: Isopropyl Myristate, Smix: Tween 80 and propylene glycol

Table 2: Ternary diagram optimization model

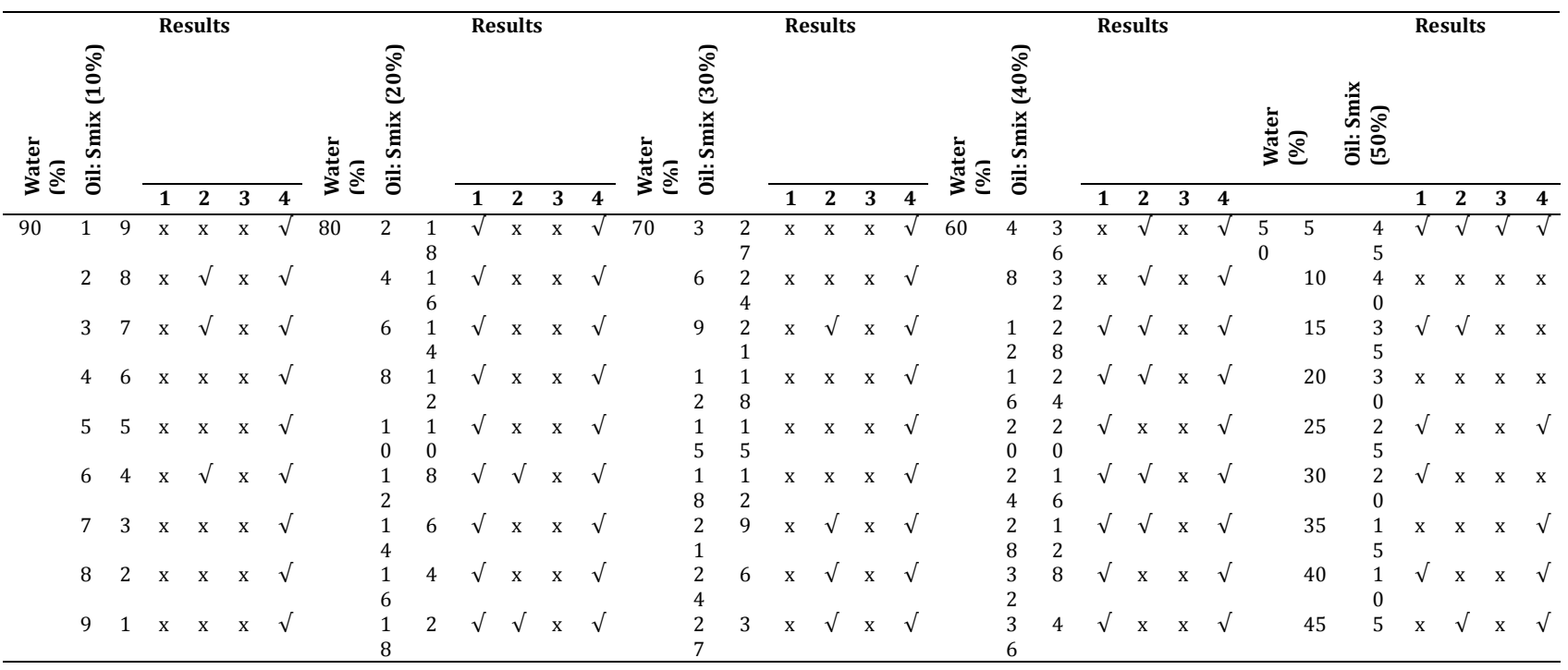

Explanation: 1 = Globul Size $(\mathrm{nm})<500,2=$ Polydispersitas $(\mathrm{PDI})<0,3,3=$ Diamater Globul 90 (D90) $(\mathrm{nm})<200 \mathrm{~nm}, 4=$ Zeta Potensial, $(\mathrm{mV})> \pm 20-35$.

Tests with PSA (Particle Size Analyzer) on selected nanoemulsions obtained from particle size intensity analysis, showed an average particle size of $187.7 \mathrm{~nm}$. However, when viewed from the analytical results of D90 intensity, a particle size of $343 \mathrm{~nm}$ was obtained, meaning that from the overall formula of nanoemulsion preparation, $90 \%$ of the particles are $343 \mathrm{~nm}$. Only $10 \%$ have particle sizes below $200 \mathrm{~nm}$. Overall, this cannot be accepted as the chosen base formula because it does not follow the desired transdermal route condition, which is below $\leq 200 \mathrm{~nm}$. The PDI and zeta values obtained were 
sufficient to meet the requirements of a fairly good formula, that is, 0.2 and $-20.1 \mathrm{mV}$. In theory, 0.2 in the polydispersity index is a heterogeneity index in a sample medium of a mixture of polymers and colloids or can be said to be the level of uniformity of particle size distribution, while the value of $0.2-0.3$ is interpreted as a population distribution of homogeneous sizes which can be accepted as a mixture of polymer-based and colloidal nanoparticle preparations. When compared with other research that does not display particle size based on the developed formula [36].
Then the particle size reduction step was carried out by the high energy method, using a HPH at a capacity of 300 bar and carried out for 10 cycles for all Celastrol nanoemulgel formulas 2.5 $\mu \mathrm{g} / \mathrm{ml}, 3 \mu \mathrm{g} / \mathrm{ml}$ and $5 \mu \mathrm{g} / \mathrm{ml}$. Then the particle size was measured again using a PSA (particle size analyzer) to obtain the particle size (z-average, D10, D50, and D90), polydispersity index (PDI), and zeta potential. The results obtained from these tests obtained a particle size for the intensity distribution that was under this study's objectives, and the desired transdermal route was $200 \mathrm{~nm}$ (table 3 ).

Table 3: Results of PSA before and after HPH

\begin{tabular}{|c|c|c|c|c|}
\hline \multirow[t]{2}{*}{ Preparations formula } & \multicolumn{4}{|l|}{ Evaluation } \\
\hline & Globul size (Nanometers) & Polydispersity index (PDI) & Zeta potential (mV) & D 90 (Nanometers) \\
\hline \multirow{2}{*}{$\begin{array}{l}\text { Nanoemulsion base non } \\
\text { celastrol }\end{array}$} & 187.7 & 0.2 & -20.1 & 343 \\
\hline & \multicolumn{4}{|c|}{ Nanoemulsion Celastrol before homogenized with HPH } \\
\hline F1 & 231.03 & 0.5 & -38 & 672 \\
\hline $\mathrm{F} 2$ & 272.9 & 0.5 & -35.9 & 698 \\
\hline \multirow[t]{2}{*}{ F3 } & 325.9 & 0.5 & -27.6 & 496.3 \\
\hline & \multicolumn{4}{|c|}{ Nanoemulsion Celastrol After homogenized with HPH } \\
\hline F1 & 91.5 & 0.1 & -15 & 158.6 \\
\hline $\mathrm{F} 2$ & 99.9 & 0.1 & -24.2 & 182.3 \\
\hline F3 & 70.4 & 0.1 & -15.3 & 119.3 \\
\hline
\end{tabular}

The above results show that the nanoemulgel preparation method involving high energy had very good results and produced very small particle sizes. This phenomenon occurs due to the pressure generated by the HPH. The cycle process was repeated according to the desired particle size. From the experiment of Gotu kola extract nanoemulsion, researchers obtained an average particle size of 198.4 nm with PDI 0.329 and zeta-30.9 $\mathrm{mV}$ after using HPH with 600 bar at 8 cycles to reduce the particle sizes of nanoemulsion [37]. Akbas, Soyler and Oztop, 2018 studied capsicin nanoemulsion in chilies, had an average particle size of $65 \mathrm{~nm}$ using HPH method with 140 bars in 5 cycles. Other experiments formulated an olive oil nanoemulsion had an average particle size of $275 \mathrm{~nm}$ with a pressure of 450 bar in 4 cycles using HPH. High-pressure homogenizer method is very effective for reducing the particle sizes of colloidal dispersions [38, 39].

For the evaluation results of the Celastrol nanoemulgel preparations organoleptic test, from all doses obtained, $\mathrm{pH}$ and homogeneity showed the resulting preparations, in the form of opaque colored nanoemulgel, matched the drug dosage color index, namely FG NCP Transparant White, $\mathrm{pH}$ value 7.19 , when the preparation was complete. However, the $\mathrm{pH}$ decreased after a cycle endurance test for $12 \mathrm{~d}$ in a row. The results can be seen in (fig. 3). The $\mathrm{pH}$ reduction in these preparations is due to the Celastrol compound's physical and chemical properties, which basically have a pH between 4-6.

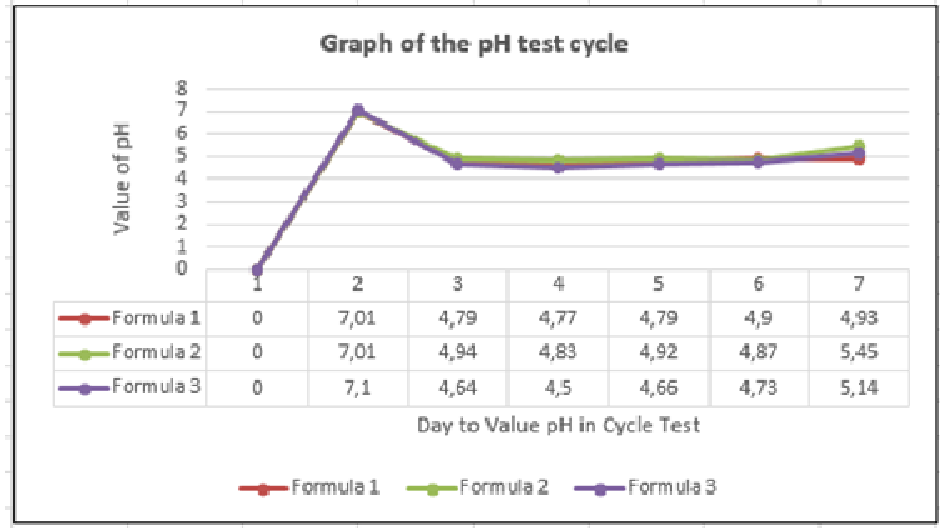

Fig. 3: Graph of the pH test cycle

The Celastrol nanoemulgel preparations were spread evenly on the transparent clear glass surface for all doses of formula made. The measurement results of the viscosity of nanoemulsion and Celastrol nanoemulgel preparations indicated that, at all dosages, the nanoemulsion viscosity values were $20 \mathrm{cP}$ and $21 \mathrm{cP}$ for nanoemulgel. This shows that the viscosity level of the two is not significantly different because the value is only 1 point difference, which can be interpreted that the preparation can flow well without flow resistance from the material composition of each preparation compiler. The flow rate (rheology) of nanoemulsion preparations seems to follow Newton's law by using spindle 1, shows a linear straight line. However, in theory, based on dispersion both suspension and colloid drug preparations tend to have a relationship with Newton's law (fig. 2). Based on testing the flow properties of celestrol nanoemulgel, using spindle no. 4 (four), the curved graphical shape is generated both up and down (fig. 4). 


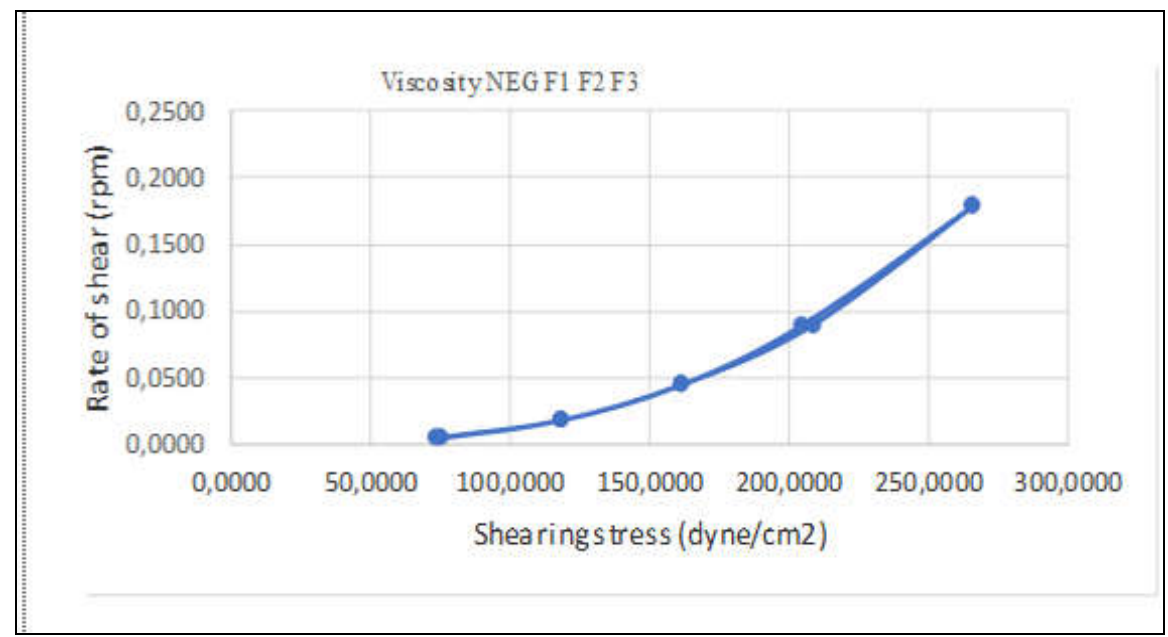

Fig. 4: Viscosity graph of celastrol nanoemulgel

The explanation in the test is that the nanoemulgel Celastrol preparation has flow properties that follow the non-Newton law of pseudoplastic type; it is caused by an increase in the shear rate of a liquid and semi-solid preparation, so the viscosity decreased. The constituent components of Celastrol nanoemulgel may cause this event because they come from the long-chain group of tween 80 , and the medium-chain triglyceride of oil. The pseudoplastic type of Celastrol nanoemulgel indicated that the preparation cannot be poured when it is in a storage container. This is shown in the graphic image, which shown that the up and down lines coincide so that each viscosity value is always different since the pseudoplastic type does not have an absolute viscosity value [40].

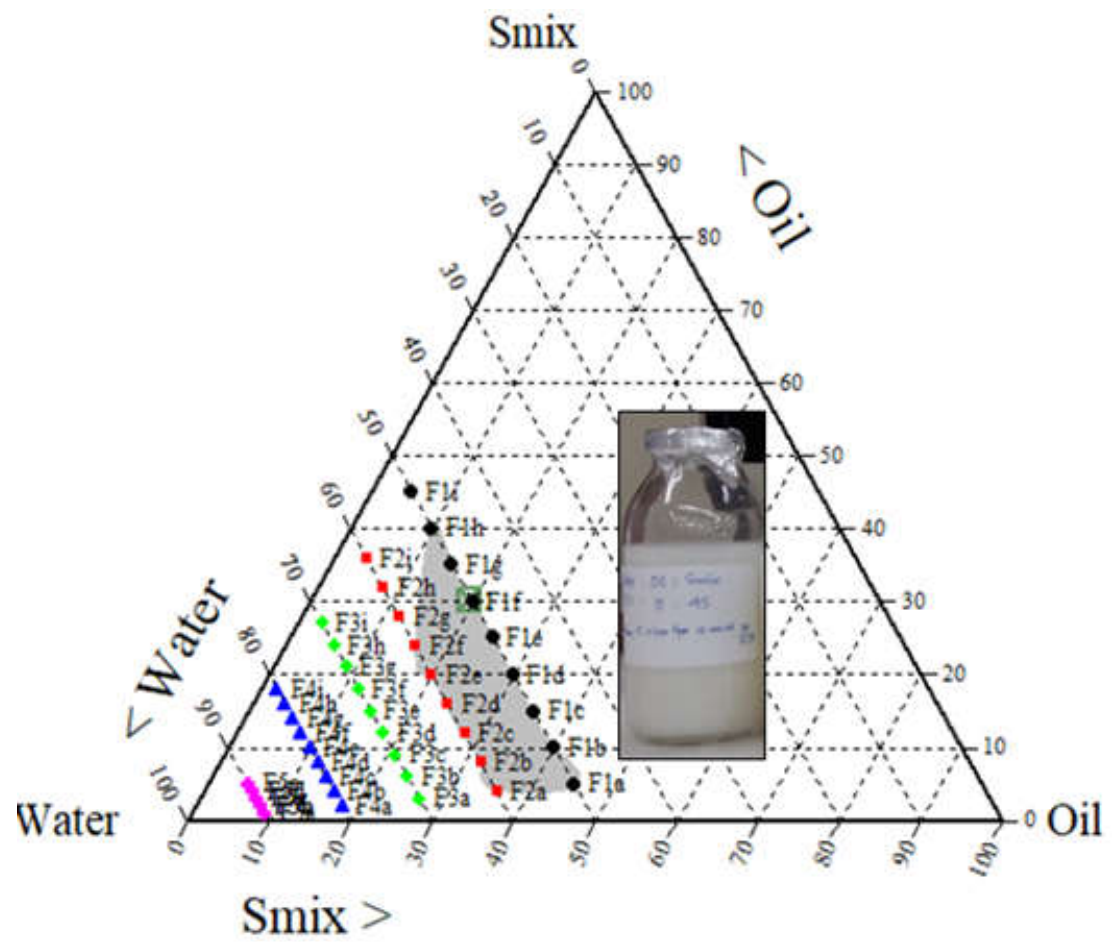

Fig. 5: The results of the ternary area nanoemulsion triangle optimization using the chemix 7.00 program

The effect of $\mathrm{pH}$ on a pharmaceutical preparation's viscosity value is significant, as seen in testing the Celastrol nanoemulgel preparation for formulas 1,2 , and 3 . The same viscosity value is $20 \mathrm{cP}$. However, the $\mathrm{pH}$ test on day 0 obtained, respectively $\mathrm{pH}$ value 7.19 for $\mathrm{F} 1,7.15$ for $\mathrm{F} 2$, and 7.09 for F3. On the 28th day, the pH value changed quite significantly.
The event was also caused by the gel-based material, namely sepigel $305^{\circledR}$, which basically consists of an emulsion-based component with an intermediate chain group that form chain bonds that extend into the flow by increasing inflow shear velocity to the next shear pressure. This affects each preparation formula's viscosity (fig. 3 and 4 ). 


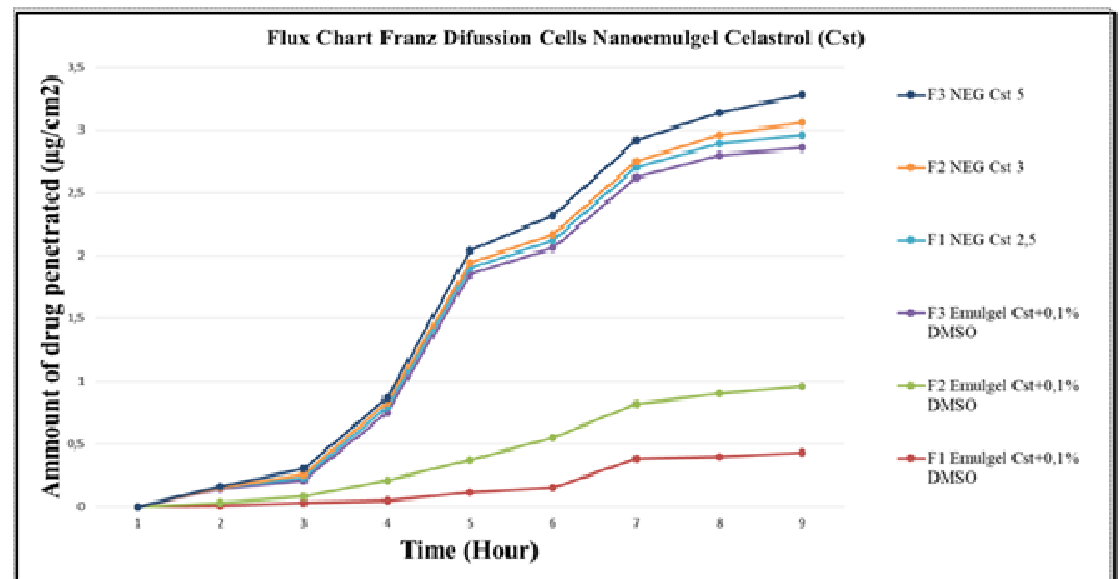

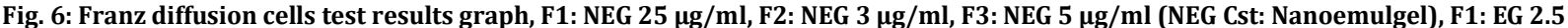
$\mu \mathrm{g} / \mathrm{ml}$, F2: EG $3 \mu \mathrm{g} / \mathrm{ml}$, F3: EG 5 g/ml (+DMSO 0.1\%) (EG: Emulgel Cst), cumulative of total Celastrol penetrated. All values were represented as mean $\pm S D(n=3)$

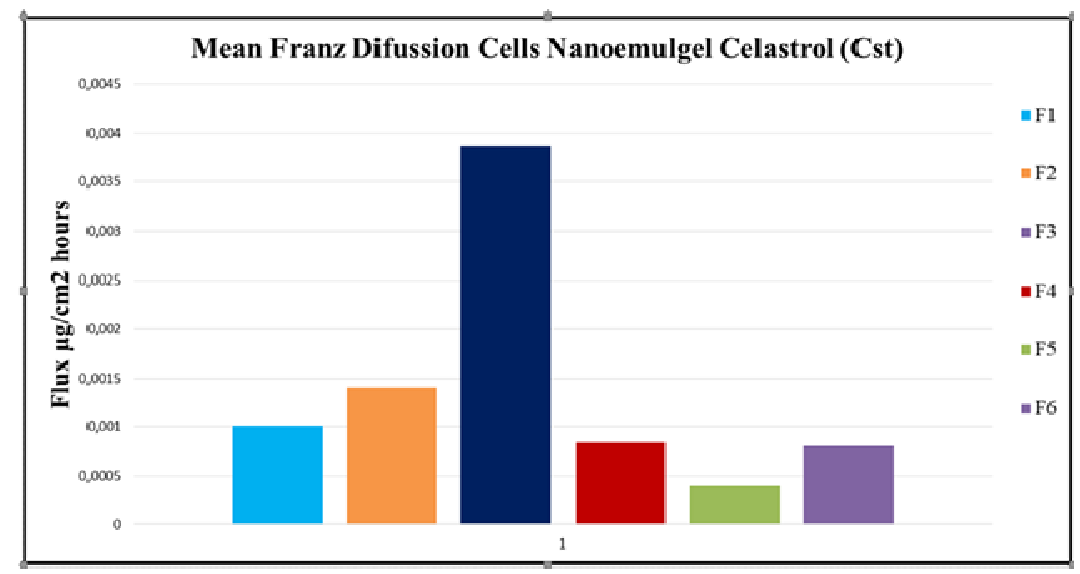

Fig. 7: Average penetration flux of nanoemulgel celastrol (Cst) and emulgel Cst+0.1\% DMSO (mean \pm SD, n=3), F1: NEG 2,5 $\mu \mathrm{g} / \mathrm{ml}, \mathrm{F2}$ : NEG 3 $\mu \mathrm{g} / \mathrm{ml}$, F3: NEG $5 \mu \mathrm{g} / \mathrm{ml}$ (NEG Cst: nanoemulgel), F1: EG $2.5 \mu \mathrm{g} / \mathrm{ml}$, F2: EG $3 \mu \mathrm{g} / \mathrm{ml}$, F3: EG $5 \mu \mathrm{g} / \mathrm{ml}$ (+DMSO 0.1\%) (EG: emulgel cst)

The results of the determination of Celastrol in the assay test in the nanoemulgel preparations obtained levels of $90.98 \%$ for $\mathrm{F} 1,91.70 \%$, and $74.50 \%$. For example, in formulation 1 with a dose of $2.5 \mu \mathrm{g} / \mathrm{ml}$ if $100 \mathrm{ml}$ of $\mathrm{v} / \mathrm{v}$ preparation were made into 100.2 grams of the dosage after adding a $305^{\circledR}$ sepigel basis, the percentage of the $2.5 \mu \mathrm{g} / \mathrm{ml}$ dose that what mixed was calculated in the whole preparation. By weighing a sample of 1.0 gram carefully and analyzing it by HPLC, the percentage of the area on the HPLC was calculated.

To determine the level of Celastrol in nanoemulgel preparations, i.e., how much Celastrol was absorbed, the adsorption efficiency (EE) of the remaining sediment was calculated after centrifuging at 4500 rpm for 30 min. The results, in F1 were $79.46 \%$, F2 $85.54 \%$ and F3 $94.54 \%$.

In vitro penetration tests, using Franz diffusion cells (CDF) (fig. 6.7), show that the formula $2.5 \mu \mathrm{g} / \mathrm{ml}$ Celastrol nanoemulgel has difficulty to penetrate the mouse skin membrane, compared to the concentrated formula $3 \mu \mathrm{g} / \mathrm{ml}$ and $5 \mu \mathrm{g} / \mathrm{ml}$. Those formulas (3 $\mu \mathrm{g} / \mathrm{ml}$ and $5 \mu \mathrm{g} / \mathrm{ml}$ ) penetrated very well through the mouse skin membrane. This can be caused by the small cumulative amount of Celastrol content in the donor compartment in formula 1 (2.5 $\mu \mathrm{g} / \mathrm{ml}$ ), affecting the level of penetration or flux. In addition, the three nanoemulgel formulas considered to have better penetration capabilities than the control formula, which is not a nano formula even the control formula is added by $0.1 \%$ DMSO to facilitate penetration. The results obtained that the nanoemulgel formula was still superior to the control formula.

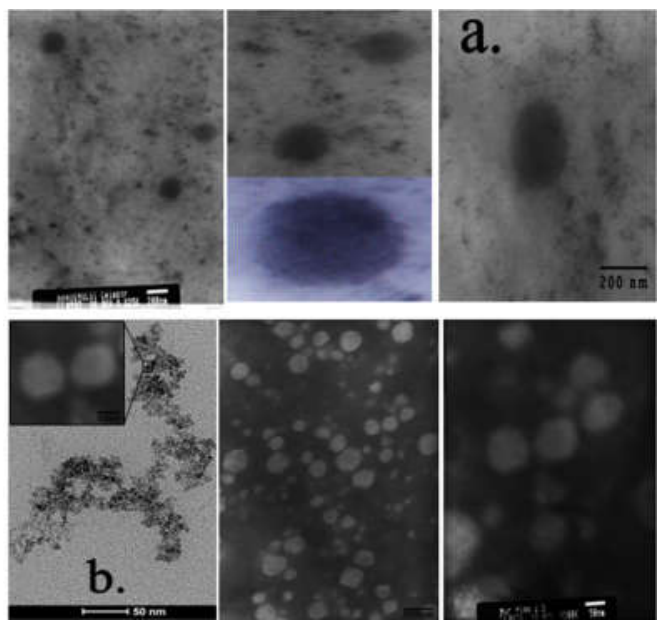

Fig. 8: TEM Morphology result a. before and b. after HPH 


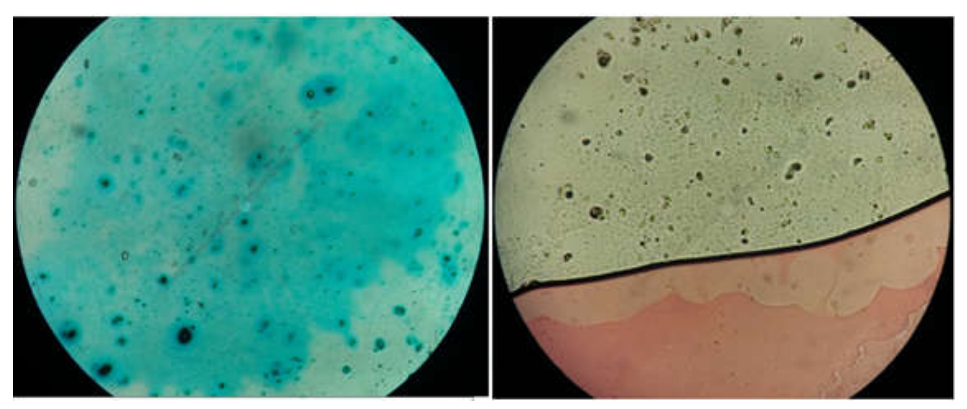

Fig. 9: Homogenity test and nanoemulgel type

Sample Detalls

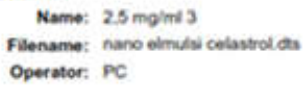

\begin{tabular}{|c|c|c|c|c|c|c|c|}
\hline Cumulant Results & \multicolumn{5}{|c|}{ Distribution Results } & \multicolumn{2}{|c|}{ Undersize Result: } \\
\hline Z.Arog (nm): 103.4 & & $(d . n m):$ & $x \operatorname{lnt}$ & 。 & sped & Dif (N) & Size $(\mathrm{dmm})$ \\
\hline Pdindex: 0.107 & Peak 1: & 1103 & 100.0 & 40.17 & 346 & 10 & 60.6 \\
\hline Pd $(\mathrm{nm}): 330$ & Peak 2: & 0.000 & 0.0 & 0.000 & 0 & 50 & 110 \\
\hline XPd: 327 & Pook 3: & 0000 & 00 & 0.000 & 0 & $\infty$ & 176 \\
\hline Derived kcpe: 160000.1 & & & & & & 100 & 205 \\
\hline
\end{tabular}
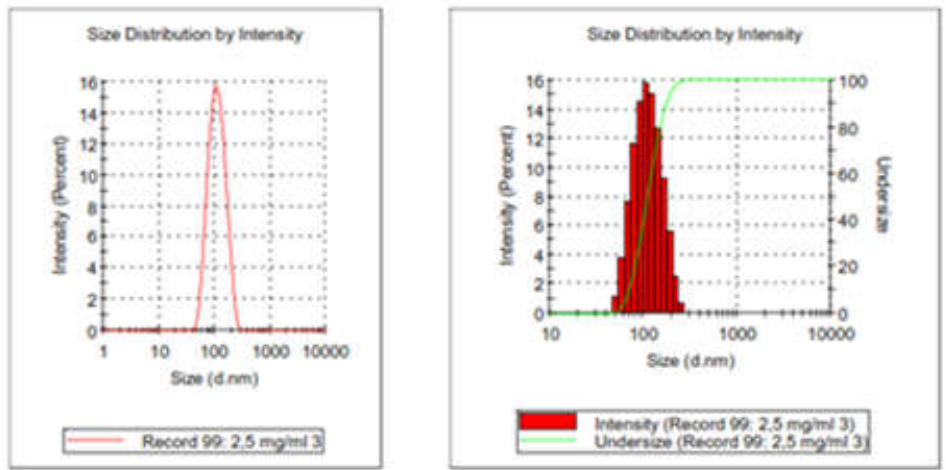

Sample Details

Narne: $3 \mathrm{mg} / \mathrm{ml} 2$

Filename: nano eimulai celastrol dits Operator: PC

Date and Time: Tuesday, November 26, 2019 3.46:00 PM SOP: mansettings nano

\begin{tabular}{|c|c|c|c|c|c|c|c|}
\hline Cumulant Results & \multicolumn{5}{|c|}{ Distribution Results } & \multicolumn{2}{|c|}{ Undersize Results } \\
\hline Z-Avg (nm): 1002 & & (d.nm): & $\%$ int & 0 & SPA & DA (w) & Size $(\mathrm{d} \cdot \mathrm{nm})$ : \\
\hline Pd Index: 0.146 & Peak 1: & 118.4 & 100.0 & 40.70 & 41.2 & 10 & 63.3 \\
\hline $\operatorname{Pd}(\mathrm{nm}): 38.3$ & Peak 2: & 0.000 & 0.0 & 0.000 & 0 & so & 109 \\
\hline YPA: 38.2 & Peak 3: & 0.000 & 0.0 & 0.000 & 0 & $\infty$ & 189 \\
\hline Derived kcps: 107312.5 & & & & & & 100 & 342 \\
\hline
\end{tabular}
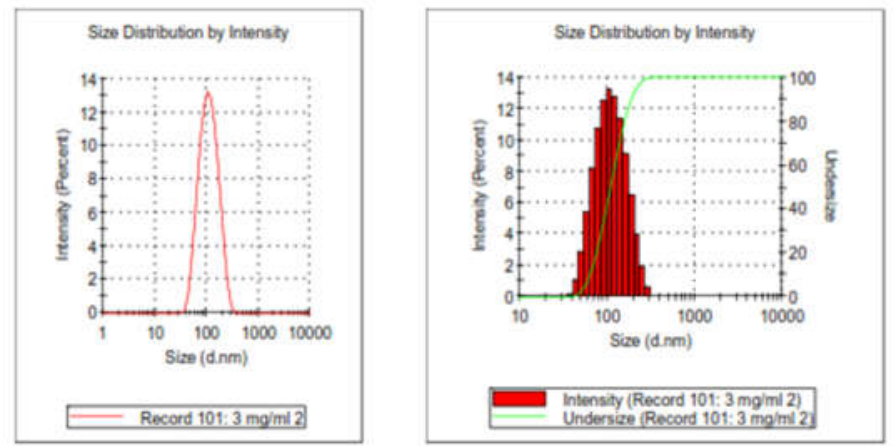


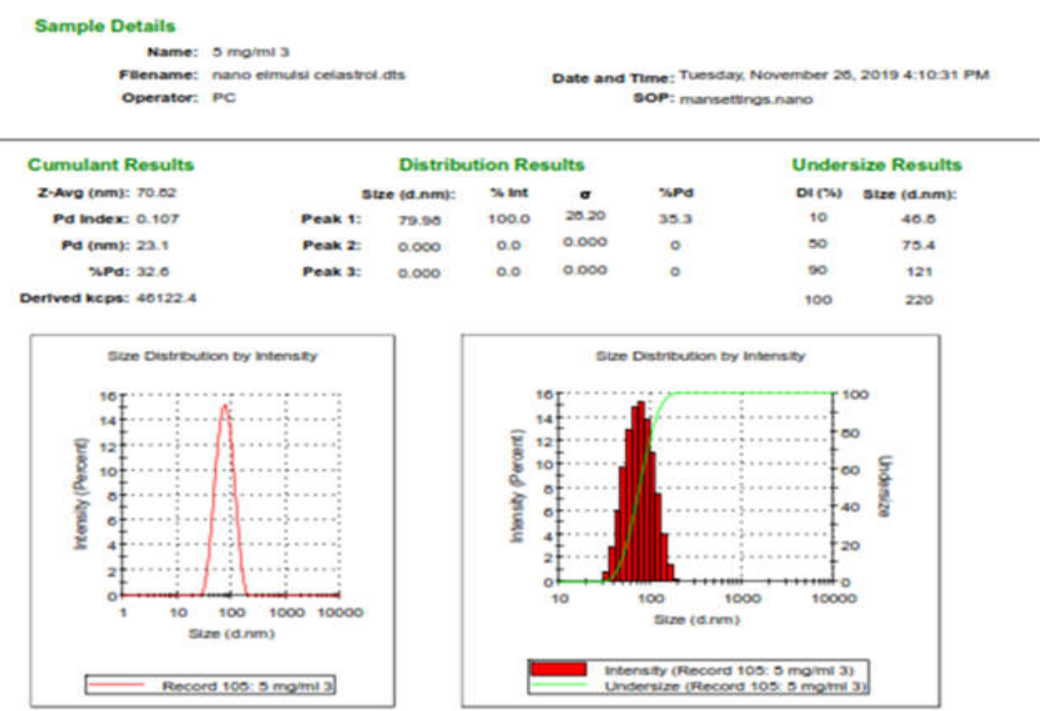

Fig. 10: Particles size analyser (PSA)

\section{CONCLUSION}

Transdermal nanoemulgel containing Celastrol has been developed successfully to obtain a nanoemulsion area that is suitable for the purpose of the transdermal route of $\leq 200 \pm 2 \mathrm{~nm}$.

By using Celastrol as an active ingredient, 5\% isopropyl myristate (IPM) as the oil phase, tween 80 , and propyleneglycol (PG) are both referred to as smix $45 \%$ and $50 \%$ water, in comparison $(5: 45: 50)$. The combination of these preparations resulted in the size of the particle size of globules for the average D90 in each preparation formula made was $2.5 \mu \mathrm{g} / \mathrm{ml} 176 \pm 2 \mathrm{~nm}, 3 \mu \mathrm{g} / \mathrm{ml} 189 \pm 2 \mathrm{~nm}$, and 5 $\mu \mathrm{g} / \mathrm{ml} 121 \pm 2 \mathrm{~nm}$. The potential zeta values obtained were- $14.6 \mathrm{mV}$,$24.8 \mathrm{mV},-4.86 \mathrm{mV}$, and the PDI value for all formulas was 0.1 . In vitro test results of all transdermal nanoemulgel Celastrol preparations produced better penetration than control preparations containing Celastrol+0.1\% DMSO gel.

\section{ACKNOWLEDGMENT}

The authors gratefully acknowledge to Directorate of Research and Community Engagements of Universitas Indonesia for financial support: Hibah Q1Q2 No: NKB-0200/UN2. R3.1/HKP.05.00/2019.

\section{FUNDING}

$\mathrm{Nil}$

\section{AUTHORS CONTRIBUTIONS}

Nur Alam Abdullah conducted a validation method of nanoemulsion formula using Chemx program 7.00, conducted nanoemulsion formulation and evaluation, HPLC analysis, interpreted the results, wrote the manuscript draft. Mahdi Jufri was responsible for supervising the experiments and secured financial support. Abdul Mun'im and Fadlina Chany Saputri reviewed and edited the manuscript. All 4 authors have read the and approved the final version of the manuscript.

\section{CONFLICT OF INTERESTS}

The authors declared that they have no conflict of interest

\section{REFERENCES}

1. Xinqiang S, Yu Z, Erqin D, Hongtao D, Lei W. International immunopharmacology mechanism of action of celastrol against rheumatoid; 2019. DOI:10.1016/j.intimp.2019.105725

2. Joshi V, Venkatesha SH, Ramakrishnan C, Nanjaraj Urs AN, Hiremath V, Moudgil KD, et al. Celastrol modulates inflammation through inhibition of the catalytic activity of mediators of the arachidonic acid pathway: secretory phospholipase A 2 group IIA, 5-lipoxygenase and cyclooxygenase-2. Pharmacol Res IJSI 2016;2:204-17.

3. Gunasekaran T, Haile T, Nigusse T, Dhanaraju MD. Nanotechnology: an effective tool for enhancing bioavailability and bioactivity of phytomedicine. Der Pharm Lett 2014;2 Suppl 6:84-98.

4. Peng X, Wang J, Song $\mathrm{H}$, Cui D, Li L, Li J, Liu Y. Optimized preparation of celastrol-loaded polymeric nanomicelles using rotatable central composite design and response surface methodology. J Biomed Nanotechnol Int J Drug Delivery 2012;3:83-94.

5. Meng S, Sun L, Wang L, Lin Z, Liu Z, Xi L, Wang Z. Colloids and surfaces B: Biointerfaces loading of water-insoluble celastrol into niosome hydrogels for improved topical permeation and anti-psoriasis activity. Colloids Surf B 2019;15:373-9.

6. Kang Q, Liu J, Zhao Y, Liu X, Liu X, Wang Y. Transdermal delivery system of nanostructured lipid carriers loaded with celastrol and indomethacin: optimization, characterization and efficacy evaluation for rheumatoid arthritis. Artif Cells Nanomed Biotechnol 2018;46 Suppl 3:585-97.

7. Song J, Shi F, Zhang Z, Zhu F, Xue J, Tan X. Jia X. Formulation and evaluation of celastrol-loaded liposomes. Molecules 2011;16:7880-92.

8. Freag MS, Saleh WM, Abdallah OY. Self-assembled phospholipid-based phytosomal nanocarriers as promising platform for improving oral bioavailability of the anticancer celastrol. Int J Pharm 2018;535:18-26.

9. Gupta A, Eral HB, Hatton TA, Doyle PS. Nanoemulsions: formation, properties and applications. Increasing in vitro penetration. Asian J Pharm Clin Res 2017;10:294-8.

10. Alvarado HL, Abrego G, Souto EB, Garduño Ramirez ML, Clares B, Garcia ML, et al. Nanoemulsions for dermal controlled release of oleanolic and ursolic acids: in vitro, ex vivo and in vivo characterization. Colloids Surf B 2015;130:40-7.

11. Shaker DS, Ishak RAH, Ghoneim A, Elhuoni MA. Nanoemulsion: a review on mechanisms for the transdermal delivery of hydrophobic and hydrophilic drugs. MDPI; 2019.

12. Dubois V, Breton S, Linder M, Fanni J, Parmentier M. Fatty acid profiles of 80 vegetable oils with regard to their nutritional potential. Eur J Lipid Sci Technol 2007;109:710-32.

13. Rai VK, Mishra N, Yadav KS, Yadav NP. Nanoemulsion as pharmaceutical carrier for dermal and transdermal drug delivery: formulation development, stability issues, basic considerations and applications. Controlled Release 2018;270:203-25.

14. Syed HK, Peh KK. Identification of phases of various oil, surfactant/co-surfactants and water system by ternary phase diagram. APP Drug Res 2014;71:301-9. 
15. Yadav SA, Singh D, Poddar S. Nanoemulsion system for transdermal drug delivery of nimodipine. AJPC Res 2012;5:1-6.

16. Ernoviya E, Masfria M, Sinaga KR. Optimization and evaluation of topical ketoconazole nanoemulsion. AJPC Res 2018;11:5-8.

17. Galvao KCS, Vicente AA, Sobral PJA. Development, characterization, and stability of $\mathrm{O} / \mathrm{W}$ pepper nanoemulsions produced by highpressure homogenization. Food Bioproc Tech 2018;11:355-67.

18. Seppic. Sepigel TM 305; 2018.

19. Ari Susanti. Penetration of pyroxicam in the solid dispersion system across the lipid membrane of the sepigel form Surabaya Indonesia; 2005.

20. Morsy MA, Abdel latif RG, Nair AB, Shehata TM. Preparation and evaluation of atorvastatin-loaded nanoemulgel on woundhealing efficacy. Pharmaceutics 2019;11:1-15.

21. Qi J, Lu Y, Wu W. Absorption, disposition and pharmacokinetics of solid lipid nanoparticles. Curr Drug Metab 2012;13:418-28.

22. Ugur B, Cetin M, Orgul D, Taghizadehghalehjoughi A, Hac A Hekimoglu S. Formulation and in vitro evaluation of topical nanoemulsion and nanoemulsion-based gels containing daidzein. J Drug Delivery Sci Technol 2019;52:189-203.

23. Martin A. Book review: physical pharmacy: physical chemical rinciples in the pharmaceutical sciences. 3rd Ed. Drug Intelligence and Clinical Pharmacy; 2016.

24. Maha HL, Sinaga KR. Formulation and evaluation of miconazole nitrate nanoemulsion and cream. AJPC Res 2018;3:3-5.

25. Mishra. Improvement of drug penetration through the skin by using nanostructured lipid carriers (NLC). IJPPR 2016;6:1-16.

26. Peng X, Wang J, Song H, Cui D, Li L, Li J, et al. Optimized preparation of celastrol-loaded polymeric nanomicelles using rotatable central composite design and response surface methodology. J Biomed Nanotech 2012;8:491-9.

27. Gururaj. Localized in situ nanoemulgel drug delivery system of quercetin for periodontitis: MDPI; 2018.

28. Alam MS, Ali MS, Alam N, Alam MI, Anwer T, Imam F, et al. Design and characterization of topical nanostructure gel of betamethasone dipropionate for psoriasis. J Appl Pharm Sci 2012;2:148-58.

29. Mardikasari SA, Jufri M, Djajadisastra J. Formulation and in vitro penetration study of topical dosage form of nanoemulsion from genistein of sophora japonica Linn. J Ilmu Kefarmasian Indonesia 2016;14:190-8.
30. Singh BP, Kumar B, Jain SK, Shafaat K. Development and characterization of a nanoemulsion gel formulation for transdermal delivery of carvedilol. Int J Drug Dev Res 2012;4:151-61.

31. Onyeabor F, Paik A, Kovvasu S, Ding B, Lin J, Wahid A, et al. Optimization of preparation and preclinical harmacokinetics of celastrol-encapsulated silk fibroin nanoparticles in the rat. Molecules 2019;24:3271.

32. Gu Y, Tang X, Yang M, Yang D, Liu J. Transdermal drug delivery of triptolide-loaded nanostructured lipid carriers: preparation, pharmacokinetic, and evaluation for rheumatoid arthritis. Int J Pharm 2019;554:235-44.

33. Shafaat K, Kumar B, Das SK, Ul Hasan R, Prajapati SK. Novel nanoemulsion as vehicles for transdermal delivery of clozapine: in vitro and in vivo studies. Int J Pharm Sci 2013;5 (Suppl 3):126-34.

34. Abulfadhel JN Al-Shaibani, Karrar MH Al-Gburi, Karrar TKA Original article design and characterization of candesartan cilexetil oral nanoemulsion containing garlic oil. Int J Appl Pharm 2019;11:116-24.

35. Danaei M, Dehghankhold M, Ataei S, Davarani FH, Javanmard R, Dokhani A, et al. Impact of particle size and polydispersity index on the clinical applications of lipidic nanocarrier systems. Pharmaceutics 2018;10:57.

36. Akbas E, Soyler B, Oztop MH. Formation of capsaicin loaded nanoemulsions with high-pressure homogenization and ultrasonication. LWT 2018;96:266-73.

37. Hanifah M, Jufri M. Formulation and stability testing of nanoemulsion lotion containing centella asiatica extract. JYP 2018;1:2-7.

38. Yukuyama MN, Kato ETM, de Araujo GLB, Lobenberg R, Monteiro LM, Lourenço FR, et al. Olive oil nanoemulsion preparation using high-pressure homogenization and D-phase emulsification-a design space approach. J Drug Delivery Sci Technol 2019;49:622-31.

39. Zha J, Zhang Q, Li, M, Wang JR, Mei X. Improving dissolution properties by polymers and surfactants: a case study of celastrol. J Pharm Sci 2018;107:2860-8.

40. Amin N, Das B. A review on formulation and characterization of nanoemulsion. Int J Curr Pharm Res 2019;11:1-5. 